\title{
Non-invasive measurement of steroids in fish-holding water: important considerations when applying the procedure to behaviour studies
}

\author{
Alexander P. Scott ${ }^{1,9)}$, Katharina Hirschenhauser ${ }^{2)}$, Nicole Bender ${ }^{3)}$, \\ Rui Oliveira $^{4)}$, Ryan L. Earley ${ }^{5)}$, Marion Sebire ${ }^{6)}$, Tim Ellis ${ }^{1)}$, \\ Michael Pavlidis ${ }^{7)}$, Peter C. Hubbard ${ }^{8)}$, Mar Huertas ${ }^{8)}$ \& \\ Adelino Canario ${ }^{8)}$
}

$\left({ }^{1}\right.$ Centre for Environment, Fisheries and Aquaculture Science, Barrack Road, The Nothe, Weymouth DT4 8UB, UK; ${ }^{2}$ Konrad Lorenz Research Station, University of Vienna, A-4645

Gruenau 11, Austria; ${ }^{3}$ University of Bern, Institute of Social and Preventive Medicine, Finkenhubelweg 11, CH-3012 Bern, Switzerland; ${ }^{4}$ ISPA, Rua Jardim do Tabaco 34, Lisboa 1149-041, Portugal; ${ }^{5}$ Department of Biological Sciences, University of Alabama, Box 870344, Tuscaloosa, AL 35487, USA; ${ }^{6}$ University of Exeter, School of Biosciences, The Hatherly Laboratories, Prince of Wales Road, Exeter EX4 4PS, UK; ${ }^{7}$ University of Crete, Department of Biology, P.O. Box 2208, GR-71409 Heraklion, Crete, Greece; ${ }^{8}$ Centro de Ciências do Mar, Universidade do Algarve, Campus de Gambelas, Faro 8005-139, Portugal)

(Accepted: 12 June 2008)

\section{Summary}

Fish behaviourists are increasingly turning to non-invasive measurement of steroid hormones in holding water, as opposed to blood plasma. When some of us met at a workshop in Faro, Portugal, in September, 2007, we realised that there were still many issues concerning the application of this procedure that needed resolution, including: Why do we measure release rates rather than just concentrations of steroids in the water? How does one interpret steroid release rates when dealing with fish of different sizes? What are the merits of measuring conjugated as well as free steroids in water? In the 'static' sampling procedure, where fish are placed in a separate container for a short period of time, does this affect steroid release and, if so, how can it be minimised? After exposing a fish to a behavioural stimulus, when is the optimal time to sample? What is the minimum amount of validation when applying the procedure to a new species? The purpose of this review is to attempt to answer these questions

9) Corresponding author's e-mail address: Alexander.Scott@cefas.co.uk

(C) Koninklijke Brill NV, Leiden, 2008 
and, in doing so, to emphasize that application of the non-invasive procedure requires more planning and validation than conventional plasma sampling. However, we consider that the rewards justify the extra effort.

Keywords: review, fish, steroids in water, non-invasive, 11-ketotestosterone, cortisol.

\section{Introduction}

The non-invasive procedure for measuring steroids in fish-holding water has recently been comprehensively reviewed (Scott \& Ellis, 2007). Briefly, the concentrations of steroids (and their metabolites) in the blood are normally used to study the endocrinological status of individuals and how they respond to a variety of physiological, behavioural and environmental factors. However, blood sampling of fish may be problematic when fish are too small, too rare or too valuable to be bled. Also, in order to be bled, they have to be netted, exposed to air, anaesthetised and handled - all of which can alter the physiological status and behaviour not only of the individual that is being sampled, but also of other fish in the tank. One way to overcome some of these problems is to 'non-invasively' measure the amounts of steroid that are released by fish into water. In terrestrial vertebrates, this has primarily been achieved by measurement of the rate of excretion of free (i.e., without any conjugating group such as a sulphate or glucuronide) or conjugated steroid metabolites in urine (Graham, 2004), faeces (Palme, 2005), saliva (Beerda et al., 1996) or hair (Koren et al., 2002). Although measurement of steroids has also been applied to fish urine (Oliveira et al., 2001) and faeces (Oliveira et al., 1999; Turner et al., 2003), a much simpler and more direct approach is available. This is based on the fact that, in fish, free steroids are able to diffuse from the bloodstream into the water through the gills (Cravedi et al., 1993; Vermeirssen \& Scott, 1996; Sorensen et al., 2000; Ellis et al., 2005). Because this process appears to happen just as easily in reverse (Vermeirssen \& Scott, 1996; Scott et al., 2005; Maunder et al., 2007), one hesitates to refer to it as an excretory process in the same way as urination or defecation. A more apt term is probably 'leakage'. However, we will refer to it as 'release', as it is not clear yet whether the passage of all free steroids across the gills is incidental or active - conferring some advantage to the fish.

Since free steroids in the water seem mainly to be derived by passive diffusion across the gills, their rate of release should, in theory, be directly proportional to their concentration in plasma (i.e., steroid amount in water 
should be a direct proxy for steroid concentrations in plasma). So far, the theory has been borne out in practice. In at least nine studies, a positive relationship was found between the amounts of free steroid released into the water over a given period of time and the concentration of free steroid in the plasma: 17,20 $\beta$-dihydroxypregn-4-en-3-one (17,20 $\beta$-P) in goldfish (Carassius auratus; Stacey et al., 1989); 17,20 $\beta$-P in dentex (Dentex dentex; Greenwood et al., 2001); cortisol in rainbow trout (Oncorhynchus mykiss; Ellis et al., 2004; Scott \& Ellis, 2007); cortisol in Atlantic salmon (Salmo salar; Ellis et al., 2007b); 11-ketotestosterone (11-KT), androstenedione (Ad) and cortisol in stickleback (Gasterosteus aculeatus; Sebire et al., 2007); and cortisol in the convict cichlid (Cryptoheros nigrofasciatus; Wong et al., 2008: this issue). It has also been shown that the patterns of release of 17,20 $\beta$-P and testosterone (T) by female goldfish (Scott et al., 2001) and of cortisol by sea bass (Dicentrachus labrax; Fanouraki et al., 2008: this issue) closely matched changes in plasma steroid concentrations recorded in separate experiments. There has been only one published study in which a statistically significant relationship was not found - with 11-KT in the Siamese fighting fish (Betta splendens); however, sample numbers in this study were low (Dzieweczynski et al., 2006).

\section{How does one assess and interpret steroid release?}

At first glance, the non-invasive procedure in fish may seem very simple: instead of measuring steroid concentration in a single blood sample, one measures it in a sample from the tank or pond that the fish inhabits. However, this procedure rarely yields usable data because, with only a single point measurement of steroid concentration, it is not possible to disentangle how much steroid has been released in the present, how much in the past, and how much has been lost due to water replacement, degradation or reabsorption by the fish (i.e., one cannot infer the hormonal status of the fish from this single point measurement). The critical information that is needed to make judgements on the hormonal status of the fish is how much steroid the fish release over a unit period of time (referred to in this paper as the 'steroid release rate'). At the moment, it is only possible to do this in two ways (see references in Scott \& Ellis, 2007): (1) the 'static sampling procedure' which involves temporarily removing a fish from its tank, placing it in 
clean water in a sampling container for a fixed period of time; (2) the 'dynamic sampling procedure' which involves keeping the fish in carefully controlled flow-through water conditions, and taking at least two water samples in order to estimate steroid release over the time between the samples. Both methods integrate steroid release rate over time and, thus, tend to 'smooth out' fluctuations that may occur in plasma concentrations - a feature that is considered an advantage of the non-invasive procedure (Goymann, 2005). The static sampling procedure has typically been used in behavioural studies as it is simpler to perform and enables measurement of individual steroid release rates where two or more fish are present in the same tank (i.e., in a social context), but the handling presents potential problems that are discussed later in this paper.

A common misconception about the non-invasive procedure is that steroid release rates have an absolute correspondence to plasma steroid concentrations (i.e., that a release rate of $x \mathrm{ng} / \mathrm{g}$ per $\mathrm{h}$ will always correspond to a plasma concentration of $y \mathrm{ng} / \mathrm{ml}$ whatever the steroid, the study or the species). However, this is far from the truth. Although steroid release rates are strongly correlated to plasma steroid concentrations (as described above), the intercepts (and sometimes probably the slopes) of the relationships are dependent on a wide variety of factors:

(1) Gill surface area: mass-specific gill surface areas in fish can vary 100-fold between species (Graham, 2006). On the basis that free steroids mainly diffuse across the gills, one could expect similar differences in steroid release rates across species or even within species across size classes. The potential effect of size is discussed in its own section below. Oxygen availability has also been shown to influence gill surface area in cyprinids (Nillson, 2007).

(2) Changes in gill permeability and integrity: stress has been suggested to alter gill permeability. In rainbow trout, for example, it has been shown (Sloman et al., 2004) that subordinate (and presumably stressed) individuals have a higher throughput of water and increased sodium efflux across the gills compared to dominant individuals. At the moment it is not known whether this would also influence steroid release rate, but this possibility should be borne in mind when applying the non-invasive procedure to studies on fish social behaviour. It is also likely that the rate of free steroid release may be altered by water quality factors and diseases that affect the integrity of the gills (Ellis et al., 2004, 2007a) although this has yet to be proved experimentally. 
(3) Binding affinity of steroids for sex hormone binding globulin (SHBG) in plasma: steroids for which SHBG has a high affinity and capacity (e.g., T and $E_{2}$ ) should in theory be released at a slower rate than those steroids that do not (e.g., 11-KT and cortisol). The basis for this theory is that, when a steroid is bound to SHBG, it is effectively removed from solution and, thus, lowers the diffusion gradient across the gills. There is a certain amount of circumstantial evidence to support this assumption. Comparison of a range of species indicates that values for $\mathrm{E}_{2}$ and $\mathrm{T}$ tend to fall at the low end of the range of steroid release rates (Scott \& Ellis, 2007). Also, though the concentration of $\mathrm{T}$ is higher than that of $17,20 \beta$-P in the plasma of female goldfish, the opposite is true for the amounts that are released into the water (Scott et al., 2001; Scott \& Ellis, 2007). Furthermore, the rates of uptake of several steroids from the water by tench (Tinca tinca) were found to correlate positively with their ability to bind to SHBG (Scott et al., 2005). Since the amount of SHBG can vary markedly between species (Hobby et al., 2000b) and stage of sexual maturation (Hobby et al., 2000a) one might predict a marked effect on the rate of release of strongly-bound steroids such as $E_{2}$ and $T$, but little or no effect for poorly-bound steroids such as cortisol and 11-KT. This hypothesis has yet to be confirmed by experimental investigation, although preliminary work has shown that it is possible to predict how much steroid is present in an unbound (i.e., diffusible) form from information on the affinity and binding capacity of SHBG and the total amount of free steroid in the plasma (Scott et al., 2005).

(4) Steroid lipophilicity: when dogfish (Squalus acanthias) were injected with eight drugs with widely differing chemical properties (Maren et al., 1968), the lipid-insoluble ionised drugs (cf., sulphated and glucuronidated steroids) were excreted via the kidney, while the lipid-soluble non-polar drugs (cf., free steroids) diffused freely into the water across the gills; similarly, when free $17,20 \beta-\mathrm{P}$, sulphated $17,20 \beta-\mathrm{P}$ and glucuronidated $\mathrm{T}$ were injected into rainbow trout, only the free $17,20 \beta$-P was cleared via the gills (Vermeirssen \& Scott, 1996). What is not yet clear, however, is whether more subtle differences in steroid polarity are sufficient to cause differences in their relative rates of release via the gills. For example, for two steroids of similar polarity (17-hydroxyprogesterone and $\mathrm{Ad}$ ) the rates of uptake were shown to be widely different, although consistent with differences in how strongly they bound to SHBG (Scott et al., 2005). 
(5) Conversion of free steroids: it is likely that most free steroid found in the water will have followed a very simple pathway: synthesis in the gonads (sex steroids) or interrenal tissue (cortisol) $\rightarrow$ release into the bloodstream $\rightarrow$ release into the water by diffusion across the gills. However, while in the bloodstream, it is very likely that some free steroids will undergo conversion to other free steroids. It is known, for example, that fish blood cells contain a $17 \beta$-hydroxysteroid dehydrogenase (17 $\beta$-HSD) that readily converts 11-ketoandrostenedione made in the testes to 11-KT (Mayer et al., 1990) and the liver of the African catfish (Clarias gariepinus) converts testicular 11 $\beta$-hydroxytestosterone into 11-KT (Cavaco et al., 1997). Also, cortisol is rapidly converted peripherally to cortisone in fish (Pottinger \& Moran, 1993). The importance of such conversions in regulating the amounts of free steroids that can be measured in water (and plasma) is something that needs to be examined in future studies.

(6) Restriction of movement: rainbow trout held in a box with a gill dam released less $\left[{ }^{14} \mathrm{C}\right]$ methyl testosterone into the water $(38 \%$ of the injected amount) than 'free-swimming' fish held in a 51 aquarium (53\%) (Cravedi et al., 1989). Restricting the movement of dogfish also reduced the branchial release of lipid-soluble drugs (Maren et al., 1968). However, the release rates of free cortisol and melatonin by rainbow trout held in a box with a gill dam were similar to those calculated for free-swimming fish (Ellis et al., 2005).

(7) Involvement of other routes of release: although the gills appear to be the major source of free steroid release in fish (at least based on the four previously-mentioned studies carried out on two species - rainbow trout and goldfish), they are not the only source. Urine also appears to contain small amounts of free steroids (though in most cases $<10 \%$ of conjugated steroid): cortisol and 17,20 $\beta$-P in Pacific herring (Clupea harengus) and plaice (Pleuronectes platessa; Scott et al., 1991; Scott \& Canario, 1992), $\mathrm{T}$ (Moore \& Scott, 1991) and 17,20 $\beta$-P (Moore \& Scott, 1992) in Atlantic salmon; T and 17,20 $\beta$-P in rainbow trout (Scott \& Liley, 1994; Vermeirssen $\&$ Scott, 1996); Ad, 17,20 $\beta$-P and 17,20 $\beta, 21$-trihydroxypregn-4-en-3-one $(17,20 \beta, 21-\mathrm{P})$ in goldfish (Sorensen et al., 2000); and 11-KT in male tilapia (Sarotherodon galilaeus; Hirschenhauser et al., 2008: this issue). In this final study, concentrations of free 11-KT in urine were significantly correlated to those in plasma. Alternatively, free steroids may find their way into the water through the bile (Pottinger et al., 1992), mucus (Schultz et al., 2005), milt (Scott et al., 1991), ovarian fluid (Schoonen et al., 1989), seminal vesicle 
fluid (Schoonen et al., 1988) and possibly skin (Ellis et al., 2005). However, no one has yet attempted to gauge the relative importance of these other pathways compared to the gills. If such routes do contribute significant amounts of free steroid to water samples, then active events such as urination and/or defecation might compromise results.

The above list is not comprehensive. Other factors that potentially alter the rate of release of free steroids (or at least the amounts that can be measured in the water) include temperature, the propensity of the fish to reabsorb the steroids, metabolism and adsorption of the steroids (by biota and container walls).

The existence of factors other than plasma steroid concentration that are able to regulate the rate of release of free steroids should not deter anyone from applying the non-invasive procedure. All it means is that careful thought needs be given to experimental design so that the factors that affect release rate are controlled (or, at the very least, acknowledged and considered in the interpretation of results).

\section{How does one take fish size into account in experiments where fish have markedly different sizes?}

It is standard practice to correct physiological measurements related to the metabolism of the focal animal by adjusting for the body size of the individual (West \& Brown, 2005). Therefore, in most published studies, steroids released into the water (per unit of time) have been scaled to body mass i.e., dividing amount of steroid released into the water by body mass (Scott $\&$ Ellis, 2007). This is considered a valid approach when all fish are of a roughly similar size. However, where fish are of markedly different sizes, the potential effect of body size on the release process needs to be considered.

For any 3-dimensional object with fixed relative dimensions, i.e., a constant shape, an increase in length by a factor of $x$ will be accompanied by an $x^{2}$ increase in surface area and an $x^{3}$ increase in volume $(\approx$ mass $)$. Thus, the surface area of the gills would be expected to be proportional to mass ${ }^{2 / 3}$. To illustrate this, when a fish grows from 4 to $10 \mathrm{~g}$ (i.e., an increase of $250 \%$ ), the gill surface area increases by only $184 \%$. On this basis, a 10-g fish should release steroid at roughly twice the rate as a 4-g fish. There are only two 
studies (Bender et al., 2006; Bender et al., 2008), both on Neolamprologus pulcher, that have applied the non-invasive procedure to fish of markedly different sizes (between 3 and $12 \mathrm{~g}$ ). The data in these studies provided no evidence that fish of ca. $10 \mathrm{~g}$ released twice as much steroid as fish of ca. $4 \mathrm{~g}$ - in fact, both size groups seemed to release very similar amounts of steroid over the same time interval. These results, however, should not be accepted as evidence that steroid release rate does not increase in relation to body size. This is because a key bit of information is missing from these studies, viz., plasma steroid concentrations. The question about whether steroid release rate is related to body size will only be answered when experiments have been carried out that include both body size and plasma steroid concentrations as covariates.

\section{Is it worth measuring conjugated steroids?}

Over the last ten years, researchers applying the non-invasive procedure in fish to behavioural studies have diverged into two 'schools' - those measuring free steroids only and those measuring the free, sulphated and glucuronidated steroid fraction (and more often than not reporting the combined levels as 'total' steroid).

A disadvantage of measuring conjugated steroids is that their pathways from synthesis to release are far more complicated than in the case of free steroids. Sulphation and glucuronidation of steroids can take place not just in the liver (as a primary means of deactivating the steroids and making them more water soluble) but also directly in the gonads of some species (Scott \& Vermeirssen, 1994). Additional complexity is conferred by the fact that the conjugated steroids can be temporarily 'stored' in the bile and urine and their release is, thus, subject to factors such as glomerular filtration rate, urination frequency, feeding, gut passage time and defecation.

Only a single study has been carried out on the specific routes of release of sulphated vs. glucuronidated steroids in teleost fish. That study showed that tritiated 17,20 $\beta$-P-sulphate injected into the blood stream of rainbow trout was mainly excreted via the urine, whereas glucuronidated $\mathrm{T}$ was mainly transferred to the bile (Vermeirssen \& Scott, 1996). However, one should be cautious in generalising this finding to other fish and to other steroids. In goldfish, for example, equal amounts of glucuronidated and sulphated 
17,20 $\beta$-P could be found in the urine (Sorensen et al., 2000), whereas when rainbow trout were injected with tritiated free cortisol (Idler \& Truscott, 1972), little or no radioactivity was recovered in the urine.

A perceived advantage of measuring all three moieties (i.e., free, sulphated and glucuronidated) is that one is measuring 'total' steroid release. However, this does not consider the fact that steroids are often metabolised into other steroids in addition to being conjugated. In rainbow trout, for example, little or no cortisol was found in the conjugated steroid fraction of the bile, but there were very large amounts of $5 \beta$-reduced metabolites of both cortisol and cortisone (Pottinger et al., 1992). Also, in reproductively mature male and female plaice (Scott et al., 1998; Vermeirssen et al., 1998) and wolffish (Anarhichas lupus; Tveiten et al., 2000) the amounts of sulphated $5 \beta$-reduced $17,20 \beta$-P in plasma and/or urine hugely exceeded the amounts of intact $17,20 \beta$-P in all three fractions combined.

Despite the complexities of origin, metabolism and routes of excretion of conjugated steroids, in the few studies where they have been measured in water, their rates of excretion (either measured directly in urine or in the water) have yielded remarkably consistent and meaningful data. For example, conjugated T, 17,20 $\beta$-P and 17,20 $\beta, 21-\mathrm{P}$ in gonadotropin-injected female goldfish (Scott \& Sorensen, 1994) and T in male goldfish (Sorensen et al., 2005 ) were released in a regular pattern that in some cases followed the free steroid peaks by a few hours; the levels of conjugated $\mathrm{T}$ and 17,20 $\beta$-P in female rainbow trout urine followed the pattern of changes of $\mathrm{T}$ and 17,20 $\beta$-P in plasma and stage of maturity of the fish (Scott \& Liley, 1994); the rates of release of both sulphated and glucuronidated $17,20 \beta$-P by GnRH-injected dentex were positively correlated to plasma 17,20 $\beta$-P concentrations (Greenwood et al., 2001) - though their coefficients of correlation were lower than for free $17,20 \beta$-P.

Situations when it might be considered an advantage to measure conjugated in addition to (or instead of) free steroids include:

(1) Measurement of conjugated steroids has been shown to reveal behavioural and physiological strategies that would be missed (and would be difficult to continue to investigate) by measurement of free steroids alone. For example, the male peacock blenny (Salaria pavo) bears an accessory sex organ on its anal fin and exclusively releases sulphated 17,20 $\beta$-P into the water (Oliveira et al., 1999). Also, males of some cichlid species urinate in response to social signals, e.g., when interacting with other males (Almeida 
et al., 2005; Barata et al., 2007). These species — plus the types of behaviour that stimulates urine release - can be revealed by examining the ratio of sulphated to free steroid concentrations in water (Hirschenhauser et al., 2008: this issue).

(2) Based on the time-release studies on male and female goldfish (mentioned above), the production of some conjugated steroids lags that of the free steroids and, thus, probably represents an estimate of what was happening to the fish several hours prior to the sampling. This fact could be useful for: field studies; for experiments where critical hormone changes take place at inconvenient times (e.g., at night); and for overcoming the 'handling effect' of the static sampling procedure (see below).

(3) Some conjugated steroids are used by fish as pheromones and, thus, they need to be measured to study how and when they are released, and to understand the basis for the behavioural/physiological reactions they elicit in 'receivers'. In fact, this was the original impetus for measuring conjugated steroids in fish water (Stacey et al., 1989; Scott \& Sorensen, 1994; Sorensen $\&$ Scott, 1994).

In conclusion, in studies where it is the intention to use the non-invasive procedure as a direct replacement for blood sampling, we consider it sufficient to measure the free steroid fraction in water only. However, there will always be certain experiments and certain lines of research where it would be an advantage to also measure the conjugated steroids. In such situations, we recommend, however, that the different fractions are reported separately not as 'combined' or 'total'.

\section{Does the static sampling procedure induce a 'handling effect' on steroid release?}

As stated above, the static sampling procedure (i.e., where the fish is taken out of its tank and placed in a small sampling container for 30 to $60 \mathrm{~min}$ ) has been the method of choice for behavioural studies. It has to some extent been assumed that this mildly intrusive procedure would have little effect on steroid production and release by the fish. However, we now have to accept that the procedure constitutes a stressor, and that $30 \mathrm{~min}$ is more than enough time for some of the cortisol produced in response to this stress to be released into the container. For instance, there was a significant increase in cortisol 
release (compared to controls) within $30 \mathrm{~min}$ in three different species that were subjected to ship noise while being held in a container (Wysocki et al., 2006). Experiments on salmon under flow-through conditions also showed a significant three-fold increase in cortisol concentrations within $30 \mathrm{~min}$ of handling stress (Ellis et al., 2007b). Dr Ryan Earley reported at the Faro Workshop (unpublished data) that if fish were transferred from their home tanks to sampling containers every day for $30 \mathrm{~min}$, the amount of cortisol that they released decreased significantly over a 4-day period (i.e., they appeared to habituate to the handling and temporary confinement). This suggests one approach to diminishing, or possibly even abolishing, the handling effect on cortisol production. Another approach might be to make the length of the sampling period as short as possible (e.g., $10 \mathrm{~min}$ instead of $30 \mathrm{~min}$ ). However, such a step could, by reducing the total amounts of steroid collected, limit the number of assays for other steroids that could be carried out on the extract. Yet a third approach (already mentioned above) is to measure a conjugate of cortisol or one of its metabolites, as these lag the production of free cortisol and, thus, take much longer than $30 \mathrm{~min}$ to respond to the handling stress (Pottinger et al., 1992).

Unfortunately, the static sampling procedure also appears to be able to influence the production and/or release of steroids other than cortisol. A perceived advantage of the non-invasive procedure is that a fish can be sampled both before and after a behavioural interaction and, thus, potentially act as its own control. However, it has been noted in a number of studies (Schreck, 1972; Pickering et al., 1987; Scott \& Canario, 1990; Kubokawa et al., 1999; Vermeirssen et al., 2000) that fish sampling is followed within 30 to $60 \mathrm{~min}$ by a significant decrease in plasma androgen concentrations. A similar significant decrease was found in rate of release of 11-KT into water by male sticklebacks (Sebire et al., 2007) and in the concentration of 11-KT in the urine of male tilapia (Oliveira et al., 2005). In this latter study, a proposal was made that the drop might be due to a natural diurnal variation of androgen secretion. However, no diurnal pattern of either T or 11-KT release was found in the bluebanded goby (Lythrypnus dalli) (Lorenzi et al., 2008) and, in the two studies in which both possibilities were specifically tested (i.e., handling v. diurnal changes), it was only the repeatedly handled fish that showed a significant drop in plasma androgen concentrations (Schreck, 1972; Pickering et al., 1987). Another study on rainbow trout and brown trout 
(Salmo trutta) suggested that the drop could be mimicked by implanting cortisol (Carragher et al., 1989). Whether or not stress associated with handling or confinement is the primary cause, procedures that involve 'before' and 'after' measurements should not be adopted until it has been clearly demonstrated whether or not handling reduces androgen (and indeed any steroid) production and, if so, how long it is before the fish recover their normal response. In the study in which brown trout were subjected to an acute stress, it took up to $24 \mathrm{~h}$ for $\mathrm{T}$ and 11-KT concentrations to return to their original concentrations (Pickering et al., 1987).

\section{When should fish be sampled after exposure to a stimulus?}

When designing experiments in which one subjects a fish to a test stimulus (e.g., placing a male with a female) and then takes a sample (either blood or water) for steroid analysis, it is important to know how long it takes for the fish to mount a response. The pattern of response of most compounds to a stimulus follows a roughly bell-shaped curve, with the optimum time for sampling generally being when the curve reaches its peak. Unfortunately, this is something that can only be determined experimentally. In fish, the time to maximum steroid release rate (Table 1) varies depending on whether it is a reproductive steroid (between 2 and $18 \mathrm{~h}$ ) or a stress steroid (between 0.5 and $4 \mathrm{~h}$ ), whether it is the free or conjugated form of the steroid that is being measured, and whether it is an androgen or progestagen. The speed of response is probably also dependent on temperature and, in the case of the sex steroids, on the stage of maturation of the gonads, i.e., how much they are 'primed' to respond. It is also important to note that in a flow-through system, there will be a lag between the time that a steroid reaches its maximum release rate and the time that it reaches its maximum concentration in the water (Ellis et al., 2004; Lower et al., 2005).

\section{What is the minimum amount of validation required for applying the non-invasive procedure to a new species?}

There are several different ways to firstly extract steroids from water samples and secondly to measure them. However, discussion of their relative merits is outside the scope of this present review. All the groups presently working 
Non-invasive measurement of steroids in fish-holding water

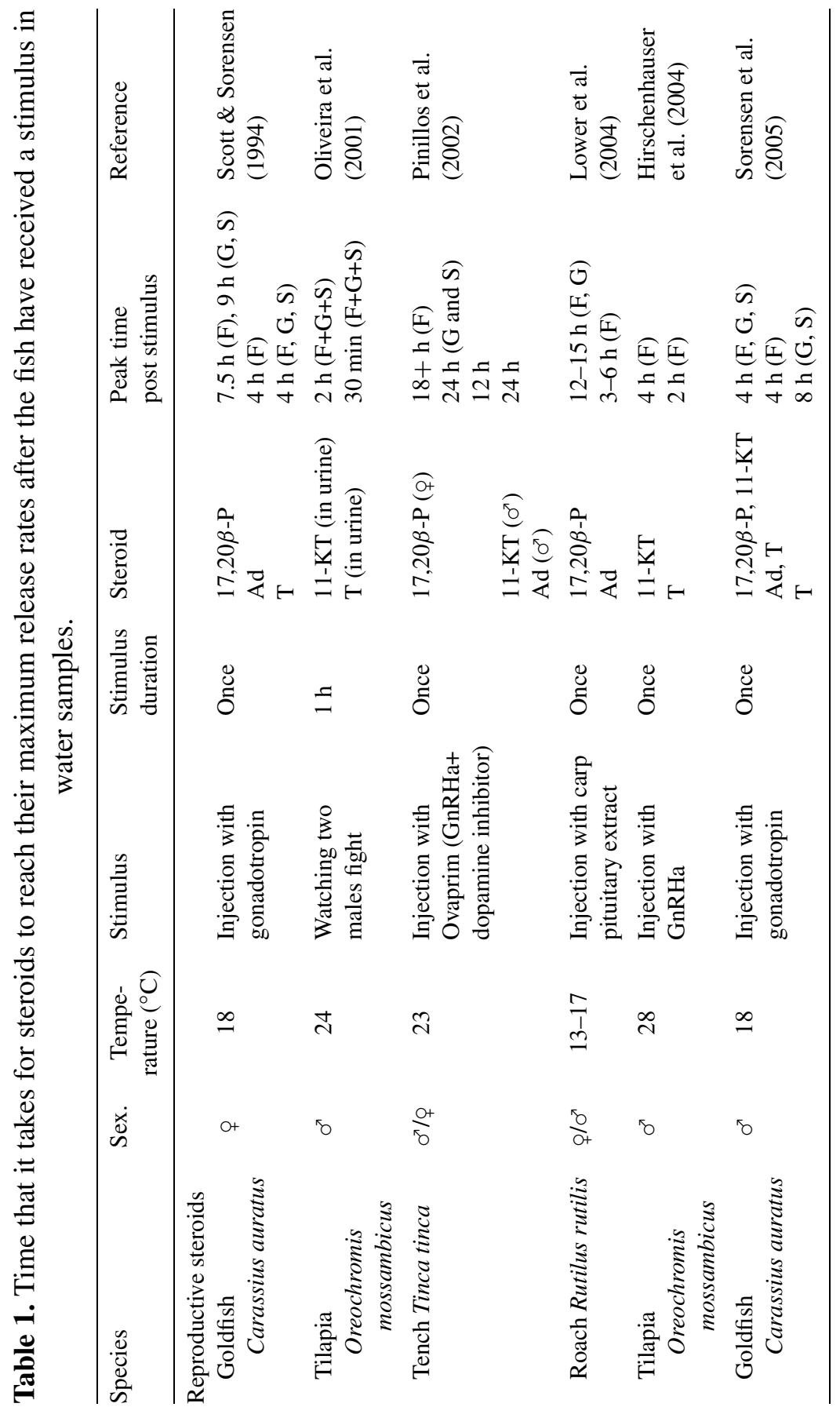




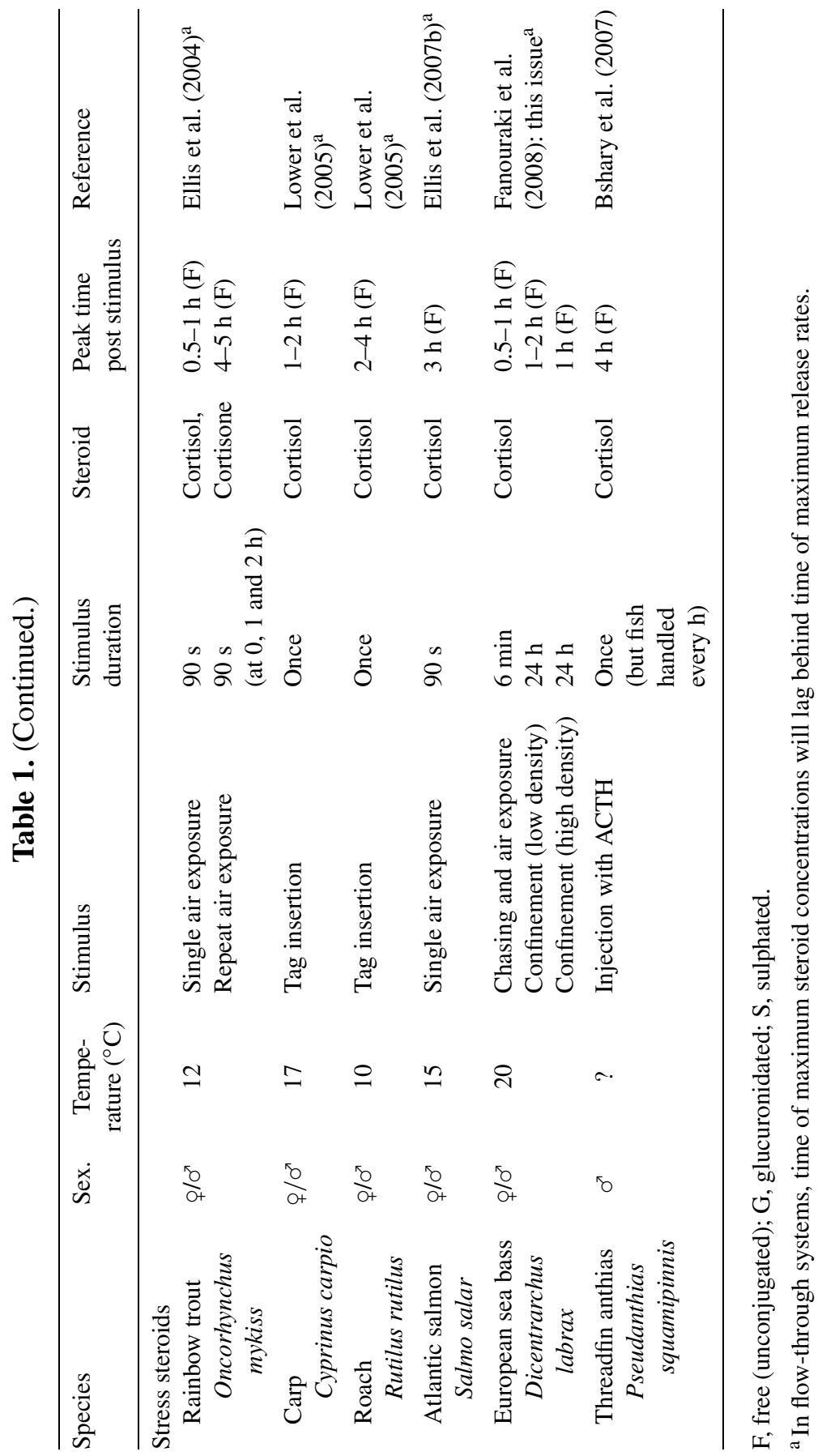


in the field of fish behaviour use solid phase extraction of steroids followed by radio- or enzyme-immunoassay. Very few problems have been reported with the application of these procedures, and when they have (Ellis et al., 2004), they have been resolved. The most likely problem to be encountered is with the extraction from water of compounds that interfere with the immunoassays and yield false positive results (so-called 'matrix effects'). In some situations (e.g., when trying to measure steroids in large volumes or water samples collected in the field) this can be a major problem, the solution to which may be relatively difficult and expensive (Lopez de Alda \& Barcelo, 2001). However, fish behaviour scientists generally have the luxury of being able to provide the fish with clean 'problem-free' water. Also, if using the static sampling procedure in conjunction with small fish, they only need to use small volumes of water $(50-100 \mathrm{ml})$.

Whatever procedures are chosen, researchers should still validate their extraction procedure and assays. We recommend the following steps:

(1) Check during every experiment that the water provided to the fish has little or no background activity and/or interference.

(2) Add known and appropriate amounts of steroids to some water samples to check that there is an acceptable (80-100\%) and consistent rate of recovery after extraction.

(3) Ensure there is parallelism between extracts and standards.

(4) Check the specificity of the procedure by separating water extracts on thin-layer or high-performance liquid chromatography (to verify that the steroid is recovered in its expected elution position).

(5) If water samples cannot be processed immediately, check for how long they can be left untouched, chilled or frozen without loss of activity.

(6) Check the 'robustness' of the procedure by giving the fish at least one physiological challenge to check that they respond in a biologically meaningful manner (i.e., a positive control). For example, injection of ACTH or application of acute stress should result in dose-dependent increases in the release of cortisol; GnRH or gonadotropin injection into sexually mature fish should also induce a dose-dependent increase in the release of sex steroids.

(7) If carrying out experiments involving physiological or behavioural challenges, carry out a time-course study to determine the optimum time between the experimental treatment and the peak of steroid release, noting that it is very likely that the peaks of androgens and progestagens (and free and conjugated steroids) will be at different times. 
(8) If the experiment involves sampling the same fish more than once, it is also necessary to check whether there is any handling effect (or diurnal variation) that might affect the release of any of the steroids.

(9) If the experiment involves fish that fall into different size groups, it would be necessary to investigate release rates of steroids in relationship to steroid concentrations in plasma as well as to fish size.

Validation studies are very time consuming and expensive, and, thus, it is fair that people should ask the question when applying the procedure to a new species 'does one have to carry out all the validation steps?'. Unfortunately, the correct answer is 'most, if not all, of them'. There is huge variation in fish steroid biosynthetic pathways (Kime, 1993), steroid release rates (Scott $\&$ Ellis, 2007) and fish-holding conditions. With the field being relatively young, there is presently insufficient information to confidently state that a procedure that has been fully validated in one species - e.g., rainbow trout living in relatively clean and cool fresh water (Ellis et al., 2004) - can be applied without problem to another that lives in organically rich and warm water. There may well be no problem. However, without proper validation, this can only be an assumption.

\section{Conclusion}

The measurement of steroids in fish-holding water provides a non-invasive alternative to blood sampling, commensurate with the protocols for (and ethics of) behavioural experiments. However, the non-invasive approach requires a thorough appreciation of potential problems associated with sampling, processing, validation and interpretation of results. It requires, for example, the measurement of steroid release rates, and not just simple measurement of a steroid water concentration. Many factors (including probably fish size) can have a significant impact on steroid release rates and these must be controlled when designing experiments and interpreting the results. Although it may be useful to measure the sulphated and glucuronidated steroid fractions in water extracts, it should be sufficient in most cases to measure the free steroid only. The static sampling procedure has a drawback in that the capture and confinement in a sampling container constitutes a stressor to the fish. Even with a relatively short sampling period of $30 \mathrm{~min}$, the fish mounts a detectable cortisol response, and the stress may also cause a temporary decrease in androgen production. Possible solutions to this problem 
have been proposed. It is considered impossible to accurately predict the optimum time between application of a behavioural stimulus and maximum steroid release, and it, therefore, needs to be established experimentally at the start of any behavioural study. Although the extraction and assay of steroids does not appear to present a major methodological problem - especially when experiments are carried out in the laboratory where water quality is usually good - we still advise validation of the procedure (especially when applying it to new species and new water conditions).

\section{Acknowledgements}

We thank Erich Möstl for thoughtful comments on an earlier version. Scott, Bender and Sebire acknowledge financial support from EC COST action 867 for attendance at the Faro workshop. Scott \& Ellis acknowledge support of Defra and the European Union (6th Framework Project No 501984: Welfare and Health in Sustainable Aquaculture (WEALTH)).

\section{References}

Almeida, O.G., Miranda, A., Frade, P., Hubbard, P.C., Barata, E.N. \& Canário, A.V.M. (2005). Urine as a social signal in the Mozambique tilapia (Oreochromis mossambicus). - Chem. Sens. 30: i309-i310.

Barata, E.N., Hubbard, P.C., Almeida, O.G., Miranda, A. \& Canário, A.V.M. (2007). Male urine signals social rank in the Mozambique tilapia (Oreochromis mossambicus). Biomed. Central Biol. 5: 54. doi: 10.1186/1741-7007-5-54: 54.

Beerda, B., Schilder, M.B., Janssen, N.S. \& Mol, J.A. (1996). The use of saliva cortisol, urinary cortisol, and catecholamine measurements for a noninvasive assessment of stress responses in dogs. - Horm. Behav. 30: 272-279.

Bender, N., Heg, D., Hamilton, I.M., Bachar, Z., Taborsky, M. \& Oliveira, R.F. (2006). The relationship between social status, behaviour, growth and steroids in male helpers and breeders of a cooperatively breeding cichlid. - Horm. Behav. 50: 173-182.

Bender, N., Heg-Bachar, Z., Oliveira, R.F., Canario, A.V.M. \& Taborsky, M. (2008). Hormonal control of brood care and social status in a cichlid with brood care helpers. Phys. Behav. 94: 349-358.

Bshary, R., Oliveira, R.F., Oliveira, T.S.F. \& Canario, A.V.M. (2007). Do cleaning organisms reduce the stress response of client reef fish? — Frontiers Zool. 4: 21. doi:10.1186/17429994-4-21.

Carragher, J.F., Sumpter, J.P., Pottinger, T.G. \& Pickering, A.D. (1989). The deleterious effects of cortisol implantation on reproductive function in two species of trout, Salmo trutta L. and Salmo gairdneri Richardson. - Gen. Comp. Endocrinol. 76: 310-321.

Cavaco, J.E.B., Vischer, H.F., Lambert, J.G.D., Goos, H.J.T. \& Schulz, R.W. (1997). Mismatch between patterns of circulating and testicular androgens in African catfish, Clarias gariepinus. — Fish Physiol. Biochem. 17: 155-162. 
Cravedi, J.P., Delous, G., Debrauwer, L. \& Prome, D. (1993). Biotransformation and branchial excretion of $17 \alpha$-methyltestosterone in trout. - Drug Metab. Dispos. 21: 377-385.

Cravedi, J.P., Delous, G. \& Rao, D. (1989). Disposition and elimination routes of $17 \alpha-$ methyltestosterone in rainbow trout (Salmo gairdneri). - Can. J. Fish. Aquat. Sci. 46: 159-165.

Dzieweczynski, T.L., Eklund, A.C. \& Rowland, W.J. (2006). Male 11-ketotestosterone levels change as a result of being watched in Siamese fighting fish, Betta splendens. - Gen. Comp. Endocrinol. 147: 184-189.

Ellis, T., Bagwell, N., Pond, M., Baynes, S.M. \& Scott, A.P. (2007a). Acute viral and bacterial infections elevate water cortisol concentrations in fish tanks. - Aquaculture 272: 707-716.

Ellis, T., James, J.D. \& Scott, A.P. (2005). Branchial release of free cortisol and melatonin by rainbow trout. - J. Fish Biol. 67: 535-540.

Ellis, T., James, J.D., Stewart, C. \& Scott, A.P. (2004). A non-invasive stress assay based upon measurement of free cortisol released into the water by rainbow trout. - J. Fish Biol. 65: 1233-1252.

Ellis, T., James, J.D., Sundh, H., Fridell, F., Sundell, K. \& Scott, A.P. (2007b). Noninvasive measurement of cortisol and melatonin in tanks stocked with seawater Atlantic salmon. - Aquaculture 272: 698-706.

Fanouraki, E., Papandroulakis, N., Ellis, T., Mylonas, C., Scott, A.P. \& Pavlidis, M. (2008). Water cortisol is a reliable indicator of stress in European sea bass, Dicentrarchus labrax. - Behaviour 145: 1267-1281.

Goymann, W. (2005). Noninvasive monitoring of hormones in bird droppings: physiological validation, sampling, extraction, sex differences, and the influence of diet on hormone metabolite levels. - Ann. N.Y. Acad. Sci. 1046: 35-53.

Graham, J.B. (2006). Aquatic and aerial respiration. - In: The physiology of fishes (Evans, D.H. \& Claiborne, J.B., eds). CRC Press, Boca Raton, FL, p. 85-117.

Graham, L.H. (2004). Non-invasive monitoring of reproduction in zoo and wildlife species. - Annu. Rev. Biomed. Sci. 6: 91-98.

Greenwood, L.N., Scott, A.P., Vermeirssen, E.L., Mylonas, C.C. \& Pavlidis, M. (2001). Plasma steroids in mature common dentex (Dentex dentex) stimulated with a gonadotropin-releasing hormone agonist. - Gen. Comp. Endocrinol. 123: 1-12.

Hirschenhauser, K., Canário, A.V.M., Ros, A.F.H.R., Taborsky, M. \& Oliveira, R.F. (2008). Social context may affect urinary excretion of 11-ketotestosterone in African cichlids. - Behaviour 145: 1367-1388.

Hirschenhauser, K., Taborsky, M., Oliveira, T., Canario, A.V.M. \& Oliveira, R.F. (2004). A test of the 'challenge hypothesis' in cichlid fish: simulated partner and territory intruder experiments. - Anim. Behav. 68: 741-750.

Hobby, A.C., Geraghty, D.P. \& Pankhurst, N.W. (2000a). Differences in binding characteristics of sex steroid binding protein in reproductive and nonreproductive female rainbow trout (Oncorhynchus mykiss), black bream (Acanthopagrus butcheri), and greenback flounder (Rhombosolea tapirina). — Gen. Comp. Endocrinol. 120: 249-259.

Hobby, A.C., Pankhurst, N.W. \& Geraghty, D.P. (2000b). A comparison of sex steroid binding protein (SBP) in four species of teleost fish. - Fish Physiol. Biochem. 23: 245-256.

Idler, D.R. \& Truscott, B. (1972). Corticosteroids in fish. — In: Steroids in nonmammalian vertebrates (Idler, D.R., ed.). Academic Press, New York, NY, p. 126-252. 
Kime, D.E. (1993). 'Classical' and 'non-classical' reproductive steroids in fish. — Rev. Fish Biol. Fish. 3: 160-180.

Koren, L., Mokady, O., Karaskov, T., Klein, J., Koren, G. \& Geffen, E. (2002). A novel method using hair for determining hormonal levels in wildlife. - Anim. Behav. 63: 403-406.

Kubokawa, K., Watanabe, T., Yoshioka, M. \& Iwata, M. (1999). Effects of acute stress on plasma cortisol, sex steroid hormone and glucose levels in male and female sockeye salmon during the breeding season. - Aquaculture 172: 335-349.

Lopez de Alda, M.J. \& Barcelo, D. (2001). Review of analytical methods for the determination of estrogens and progestogens in waste waters. - J. Anal. Chem. 371: 437-447.

Lorenzi, V., Earley, R.L., Rodgers, E.W., Pepper, D.R. \& Grober, M.S. (2008). Diurnal patterns and sex differences in cortisol, 11-ketotestosterone, testosterone, and 17 $\beta$ estradiol in the bluebanded goby (Lythrypnus dalli). - Gen. Comp. Endocrinol. 155: 438-446.

Lower, N., Moore, A., Scott, A.P., Ellis, T., James, J. \& Low, P.J. (2005). A non-invasive method to assess the impact of electronic tag insertion on stress levels in fishes. J. Fish Biol. 67: 1202-1212.

Lower, N., Scott, A.P. \& Moore, A. (2004). Release of sex steroids into the water by roach (Rutilus rutilus L.). - J. Fish Biol. 64: 16-33.

Maren, T.H., Embry, R. \& Broder, L.E. (1968). The excretion of drugs across the gill of the dogfish, Squalus acanthias. - Comp. Biochem. Physiol. 26: 853-864.

Maunder, R.J., Matthiessen, P., Sumpter, J.P. \& Pottinger, T.G. (2007). Rapid bioconcentration of steroids in the plasma of sticklebacks (Gasterosteus aculeatus) exposed to water-borne testosterone and 17 $\beta$-estradiol. - J. Fish Biol. 70: 678-690.

Mayer, I., Borg, B. \& Schulz, R. (1990). Conversion of 11-ketoandrostenedione to 11-ketotestosterone by blood cells of six fish species. - Gen. Comp. Endocrinol. 77: $70-74$.

Moore, A. \& Scott, A.P. (1991). Testosterone is a potent odorant in precocious male Atlantic salmon (Salmo salar L.) parr. - Philos. Trans. Roy. Soc. B 332: 241-245.

Moore, A. \& Scott, A.P. (1992). 17 $\alpha, 20 \beta$-dihydroxy-4-pregnen-3-one 20-sulphate is a potent odorant in precocious male Atlantic salmon (Salmo salar L.) parr which have been preexposed to the urine of ovulated females. - Proc. Roy. Soc. B 249: 205-209.

Nillson, G.E. (2007). Gill remodeling in fish - a new fashion or an ancient secret? - J. Exp. Biol. 210: 2403-2409.

Oliveira, R.F., Canario, A.V.M. \& Bshary, R. (1999). Hormones, behaviour and conservation of littoral fishes: current status and prospects for future research. — In: Behaviour and conservation of littoral fishes (Almada, V.C., Oliveira, R.F. \& Gonçalves, E.J., eds). ISPA, Lisbon, p. 149-178.

Oliveira, R.F., Carneiro, L.A. \& Canário, A.V.M. (2005). Behavioural endocrinology: no hormonal response in tied fights. - Nature 437: 207-208.

Oliveira, R.F., Lopes, M., Carneiro, L.A. \& Canário, A.V.M. (2001). Watching fights raises fish hormone levels. - Nature 409: 475.

Palme, R. (2005). Measuring fecal steroids: guidelines for practical application. - Ann. N.Y. Acad. Sci. 1046: 1-6.

Pickering, A.D., Pottinger, T.G., Carragher, J. \& Sumpter, J.P. (1987). The effects of acute and chronic stress on the levels of reproductive hormones in the plasma of mature male brown trout, Salmo trutta L. - Gen. Comp. Endocrinol. 68: 249-259. 
Pinillos, M.L., Guijarro, A.I., Delgado, M.J., Hubbard, P.C., Canário, A.V.M. \& Scott, A.P. (2002). Production, release and olfactory detection of sex steroids by the tench (Tinca tinca L.). - Fish Physiol. Biochem. 26: 197-210.

Pottinger, T.G. \& Moran, T.A. (1993). Differences in plasma cortisol and cortisone dynamics during stress in two strains of rainbow trout (Oncorhynchus mykiss). — J. Fish Biol. 43: 121-130.

Pottinger, T.G., Moran, T.A. \& Cranwell, P.A. (1992). The biliary accumulation of corticosteroids in rainbow trout, Oncorhynchus mykiss, during acute and chronic stress. - Fish Physiol. Biochem. 10: 55-66.

Schoonen, W.G.E.J., Granneman, J.C.M. \& Lambert, J.G.D. (1989). Steroids and steroid glucuronides in the ovarian fluid of the African catfish, $\overline{\text { Clarias gariepinus, between }}$ ovulation and oviposition. - Fish Physiol. Biochem. 6: 91-112.

Schoonen, W.G.E.J., Lambert, J.G.D. \& Van Oordt, P.G.W.J. (1988). Quantitative analysis of steroids and steroid glucuronides in the seminal vesicle fluid of feral spawning and feral and cultivated non-spawning African catfish, Clarias gariepinus. - Gen. Comp. Endocrinol. 70: 91-100.

Schreck, C.B. (1972). Evaluation of diel variation in androgen levels of rainbow trout, Salmo gairdneri. - Copeia: 865-868.

Schultz, D.R., Perez, N., Tan, C.-K., Mendez, A.J., Capo, T.R., Snodgrass, D., Prince, E.D. \& Serafy, J.E. (2005). Concurrent levels of 11-ketotestosterone in fish surface mucus, muscle tissue and blood. - J. Appl. Ichthyol. 21: 394-398.

Scott, A.P. \& Canario, A.V.M. (1990). Plasma levels of ovarian steroids, including $17 \alpha, 21$ dihydroxy-4-pregnene-3,20-dione (11-deoxycortisol) and $3 \alpha, 17 \alpha, 21$-trihydroxy-5 $\beta$ pregnan-20-one in the ovaries of mature plaice (Pleuronectes platessa) induced to mature with human chorionic gonadotrophin. - Gen. Comp. Endocrinol. 78: 286-298.

Scott, A.P. \& Canario, A.V.M. (1992). 17 $\alpha, 20 \beta$-dihydroxy-4-pregnen-3-one 20-sulphate: a major new metabolite of the teleost oocyte maturation-inducing steroid. - Gen. Comp. Endocrinol. 85: 91-100.

Scott, A.P., Canario, A.V.M., Sherwood, N.M. \& Warby, C.M. (1991). Levels of steroids, including cortisol and $17 \alpha, 20 \beta$-dihydroxy-4-pregnen-3-one, in plasma, seminal fluid and urine of Pacific herring (Clupea harengus pallasi) and North Sea plaice (Pleuronectes platessa). — Can. J. Zool. 69: 111-116.

Scott, A.P. \& Ellis, T. (2007). Measurement of fish steroids in water - a review. - Gen. Comp. Endocrinol. 153: 392-400.

Scott, A.P. \& Liley, N.R. (1994). Dynamics of excretion of $17 \alpha, 20 \beta$-dihydroxy-4-pregnen3 -one 20-sulphate, and of the glucuronides of testosterone and $17 \beta$-oestradiol, by urine of reproductively mature male and female rainbow trout (Oncorhynchus mykiss). J. Fish Biol. 44: 117-129.

Scott, A.P., Pinillos, M. \& Ellis, T. (2001). Why measure steroids in fish plasma when you can measure them in water? - In: Perspectives in comparative endocrinology: unity and diversity: the proceedings of the 14th international congress of comparative endocrinology, Sorrento, Italy, 26-30 May, 2001 (Goos, H.J.T., Rastogi, R.K., Vaudry, H. \& Pierantoni, R., eds). Monduzzi, Bologna, p. 1291-1295.

Scott, A.P., Pinillos, M. \& Huertas, M. (2005). The rate of uptake of sex steroids from water by tench Tinca tinca L. is influenced by their affinity for sex steroid binding protein in plasma. - J. Fish Biol. 67: 182-200. 
Scott, A.P. \& Sorensen, P.W. (1994). Time course of release of pheromonally active gonadal steroids and their conjugates by ovulatory goldfish. - Gen. Comp. Endocrinol. 96: 309-323.

Scott, A.P. \& Vermeirssen, E.L.M. (1994). Production of conjugated steroids by teleost gonads and their role as pheromones. - In: Perspectives in comparative endocrinology (Davey, K.G., Peter, R.E. \& Tobe, S.S., eds). National Research Council of Canada, Ottawa, ON, p. 645-654.

Scott, A.P., Witthames, P.R., Turner, R.J. \& Canario, A.V.M. (1998). Plasma concentrations of ovarian steroids in relation to oocyte final maturation and ovulation in female plaice sampled at sea. - J. Fish Biol. 52: 128-145.

Sebire, M., Katsiadaki, I. \& Scott, A.P. (2007). Non-invasive measurement of 11-ketotestosterone, cortisol and androstenedione in male three-spined stickleback (Gasterosteus aculeatus). - Gen. Comp. Endocrinol. 152: 30-38.

Sloman, K.A., Scott, G.R., McDonald, D.G. \& Wood, C.M. (2004). Diminished social status affects ionoregulation at the gills and kidney in rainbow trout (Oncorhynchus mykiss). - Can. J. Fish. Aquat. Sci. 61: 618-626.

Sorensen, P.W., Pinillos, M. \& Scott, A.P. (2005). Sexually mature male goldfish release large quantities of androstenedione to the water where it functions as a pheromone. - Gen. Comp. Endocrinol. 140: 164-175.

Sorensen, P.W. \& Scott, A.P. (1994). The evolution of hormonal sex pheromones in teleost fish: poor correlation between the pattern of steroid release by goldfish and olfactory sensitivity suggests that these cues evolved as a result of chemical spying rather than signal specialization. - Acta Physiol. Scand. 152: 191-205.

Sorensen, P.W., Scott, A.P. \& Kihslinger, R.L. (2000). How common hormonal metabolites function as relatively specific pheromonal signals in the goldfish. - In: Proceedings of the 6th international symposium on reproductive physiology of fish, Bergen, Norway, July 4-9, 1999 (Norberg, B., Kjesbu, O.S., Taranger, G.L., Andersson, E. \& Stefansson, S.O., eds), p. 125-128.

Stacey, N.E., Sorensen, P.W., Van der Kraak, G.J. \& Dulka, J.G. (1989). Direct evidence that $17 \alpha, 20 \beta$-dihydroxy-4-pregnen-3-one functions as a goldfish primer pheromone: preovulatory release is closely associated with male endocrine responses. - Gen. Comp. Endocrinol. 75: 62-70.

Turner, J.W., Nemeth, R. \& Rogers, C. (2003). Measurement of fecal glucocorticoids in parrotfishes to assess stress. - Gen. Comp. Endocrinol. 133: 341-352.

Tveiten, H., Scott, A.P. \& Johnsen, H.K. (2000). Plasma-sulfated C21-steroids increase during the periovulatory period in female common wolffish and are influenced by temperature during vitellogenesis. - Gen. Comp. Endocrinol. 117: 464-473.

Vermeirssen, E.L.M. \& Scott, A.P. (1996). Excretion of free and conjugated steroids in rainbow trout (Oncorhynchus mykiss): evidence for branchial excretion of the maturationinducing steroid, 17,20 $\beta$-dihydroxy-4-pregnen-3-one. - Gen. Comp. Endocrinol. 101: 180-194.

Vermeirssen, E.L.M., Scott, A.P., Mylonas, C.C. \& Zohar, Y. (1998). Gonadotrophin releasing hormone agonist stimulates milt fluidity and plasma concentrations of $\overline{17,20 \beta \text {-dihydroxylated and } 5 \beta \text {-reduced, } 3 \alpha \text {-hydroxylated C21 steroids in male plaice }}$ (Pleuronectes platessa). — Gen. Comp. Endocrinol. 112: 163-177. 
Vermeirssen, E.L.M., Shields, R.J., Mazorra de Quero, C. \& Scott, A.P. (2000). Gonadotrophin-releasing hormone agonist raises plasma concentrations of progestogens and enhances milt fluidity in male Atlantic halibut (Hippoglossus hippoglossus). - Fish Physiol. Biochem. 22: 77-87.

West, G.B. \& Brown, J.H. (2005). The origin of allometric scaling laws in biology from genomes to ecosystems: towards a quantitative unifying theory of biological structure and organization. - J. Exp. Biol. 208: 1575-1592.

Wong, S., Dykstra, M., Campbell, J. \& Earley, R.L. (2008). Measuring water-borne cortisol in convict cichlids (Amatitlania nigrofasciata): is the procedure a stressor? - Behaviour 145: 1283-1305.

Wysocki, L.E., Dittami, J.P. \& Ladich, F. (2006). Ship noise and cortisol secretion in European freshwater fishes. - Biol. Cons. 128: 501-508. 